\section{Atopie: Haut und Darm eng verbunden}

\section{Allergische Reaktionen im Darm spielen offensichtlich eine Rolle bei der Sensibilisierung von Kindern mit atopischem Ekzem. Diese Hypothese wird unterstützt durch die Befunde einer zwölfmonatigen Beobachtung an Neugeborenen, bei denen fieberhafte Durchfallerkrankungen gehäuft bei Kindern mit Neurodermitis auftraten.}

Das Interesse der allergologischen Forschung wendet sich zunehmend dem Geschehen im MagenDarm-Trakt zu. Dabei werden Beobachtungen, die jedem erfahrenen Allergologen geläufig sind, näher unter die Lupe genommen. So z.B. die Tatsache, daß bei Kindern mit atopischem Ekzem (AE) häufiger eine Diarrhöe auftritt als bei Kindern ohne diese allergische Erkrankung. Welcher immunologische Zusammenhang sich dahinter verbirgt, ist bisher nur in Ansätzen bekannt.

Th. Hirsch et al. vom Universitätsklinikum Carl Gustav Carus in Dresden untersuchten deshalb über 12 Monate 92 Neugeborene mit mindestens einem erstgradigen Angehörigen mit einer atopischen Sensibilisierung.

\section{AE-Kinder: Fieberhafte \\ Diarrhöen häufen sich}

Bei 22 dieser Kinder $(23,9 \%)$ wurde im ersten Lebensjahr ein AE diagnostiziert, bei 18 Kindern $(19,6 \%)$ trat im Rahmen fieberhafter Erkrankungen eine Diarrhöe auf, wobei Durchfall mit Fieber bei den AE-Kindern signifikant häufiger $(8 / 22=36,4 \%)$ als bei den Kindern ohne AE $(10 / 70=14,3 \%)$ war. Auch wenn man externe Einflußfaktoren wie z.B. Geschwisterzahl oder regelmäßiger Kontakt zu fremden Kindern berücksichtigte, blieb der Zusammenhang signifikant: Das Risiko, im ersten Jahr eine fieberhafte Diarrhöe zu entwickeln, war bei Kindern mit AE etwa fünfmal so hoch wie bei Kindern ohne AE.

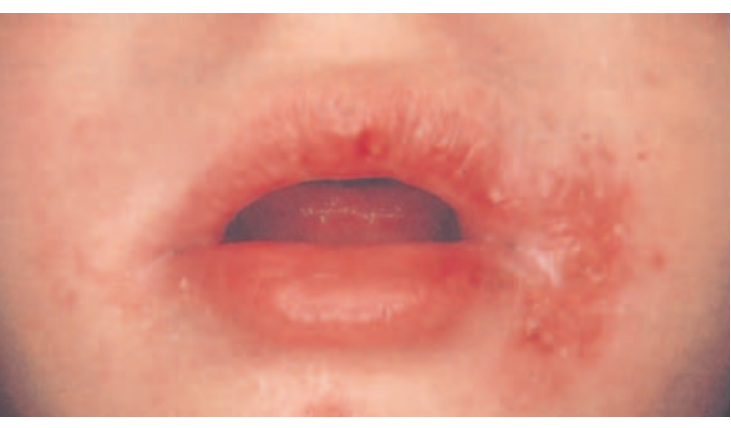

Atopiesymptome auf der Haut - sie sind eng korreliert mit dem immunologischen Geschehen im Gastroinestinaltrakt, so eine Studie an Neugeborenen.

Interessant ist dabei die Beobachtung bei den 8 Kindern mit AE und fieberhafter Diarrhöe, daß bei 7 von ihnen die ersten Atopiesymptome beobachtet wurden, noch bevor der fieberhafte Durchfall auftrat. Die immunologischen Befunde dieser Kinder wiesen ebenfalls Besonderheiten auf. Sie hatten im Alter von 12 Monaten häufiger spezifisches IgE gegen Nahrungsmittel im Serum und Gesamt-IgE im Stuhl sowie eine verminderte IFN- $\gamma$-Produktion der mononuleären Zellen als die Kinder mit AE ohne Diarrhöe oder die übrigen Kinder.

\section{Atopie begünstigt Diarrhöe-Neigung} Diese Daten, so folgern die Autoren, sprechen dafür, daß allergische Reaktionen im Darm eine Rolle bei der atopischen Sensibilisierung von Kindern mit AE spielen. Dabei geht das AE mit einer Neigung zu Durchfällen im Rahmen von Infekten einher - und nicht umgekehrt, wie von anderen Autoren behauptet. Denn ohne Berücksichti- gung der Fieberanamnese war die Prävalenz der Diarrhöe insgesamt bei den Kindern mit AE nicht höher als bei den anderen Kindern.

\section{Zusammenhänge bisher nur hypothetisch}

Als Arbeitshypothese für ihre Beobachtungen bieten die Autoren die Vorstellung einer lokalen allergischen Reaktion gegen infektassoziierte Allergene an. Dies können Erreger-assoziierte Antigene sein oder durch Entzündungsmediatoren veränderte Nahrungsmittelbestandteile, die lokale allergische Reaktionen auslösen können.

Für eine solche lokale allergische Reaktion im Darm spricht der Nachweis von IgE im Stuhl bei der Mehrzahl der Kinder. Fieber könnte bei solchen immunologischen Prozessen Ausdruck einer atopischen Entzündungsreaktion oder ein Zeichen der Intensität des Infektionsgeschehens sein, das der Reaktion im Darm vorausgeht.

Ein anderer Mechanismus könnte in der Störung der Laktobazillusflora durch in den Darm gelangte Infektionserreger bestehen. Zumindest in vitro zeigte sich, daß durch Laktobazillus GGhydrolisiertes Kasein die IL-4-Produktion mononukleärer Zellen von Atopikern hemmt, während nicht-hydrolisiertes Kasein die IL-4-Produktion stimuliert. Auch auf diesem Wege wäre eine Begünstigung IgE-vermittelter Reaktionen im Darm durch fieberhafte Infekte vorstellbar.

Endgültige Aussagen können jedoch aufgrund der geringen Fallzahl und des fehlenden Infektionsnachweises in den Fieberepisoden noch nicht getroffen werden. Dennoch sollten die Befunde dieser Studie ein weiterer Anlaß sein, Kinder mit einem Atopierisiko schon zu einem sehr frühen Zeitpunkt auf gastrointestinale Symptome bzw. Infekte hin zu untersuchen. Wenn die hier ablaufenden immunologischen Zusammenhänge besser verstanden werden, findet man möglicherweise neue Ansatzpunkte für die Prävention des atopischen Ekzems. 